\title{
Revealing the effect of Ti doping on significantly enhancing cyclic performance at a high cutoff voltage for Ni-rich $\mathrm{LiNi}_{0.8} \mathrm{Co}_{0.15} \mathrm{Al}_{0.05} \mathrm{O}_{2}$ cathode
}

Da Liu, ${ }^{\dagger}$ Siyang Liu, ${ }^{\dagger}$ Congcong Zhang, ${ }^{\ddagger}$ Longzhen You,${ }^{\dagger}$ Tao Huang $₫$ and Aishui $\mathrm{Yu}^{* \dagger, \ddagger}$

$\dagger$ Department of Chemistry, Collaborative Innovation Center of Chemistry for Energy Materials, Shanghai Key Laboratory of Molecular Catalysis and Innovative Materials, Institute of New Energy, Fudan University, Shanghai 200438, China

$\$$ Laboratory of Advanced Materials, Fudan University, Shanghai 200438, China

*Corresponding author: Phone: +86-21-51630320

E-mail: asyu@fudan.edu.cn

Table of contents of Supporting Information

Page 1: Cover sheet.

Page 2: Figure S1. TEM images of (a) NCA and (b) 1\%Ti-NCA before cycles.

Page 3: Figure S2. XPS spectra and fitted results of (a) Co $2 p$ and (b) Al $2 p$ of the NCA and $1 \%$ Ti-NCA samples.

Page 4: Figure. S3. Cyclic performance between 3.0 and $4.5 \mathrm{~V}$ at $55^{\circ} \mathrm{C}$ under $1 \mathrm{C}$ for pristine NCA and 1\%Ti-NCA.

Page 5: Figure. S4. Cyclic performance between 3.0 and $4.2 \mathrm{~V}$ at $25{ }^{\circ} \mathrm{C}$ under $1 \mathrm{C}$ for pristine NCA and 1\% Ti-NCA.

Page 6: Figure. S5. Rate performance between 3.0 and $4.5 \mathrm{~V}$ at $25^{\circ} \mathrm{C}$ for all samples. 

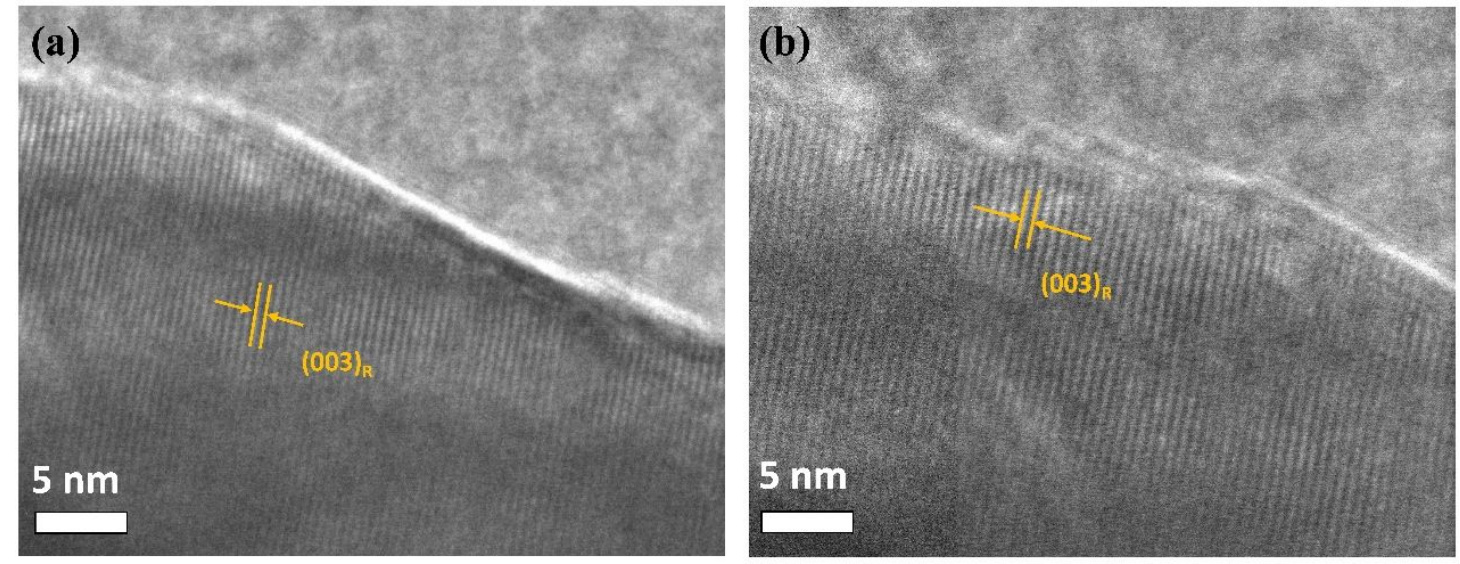

Fig. S1 TEM images of (a) NCA and (b) 1\%Ti-NCA before cycles. 

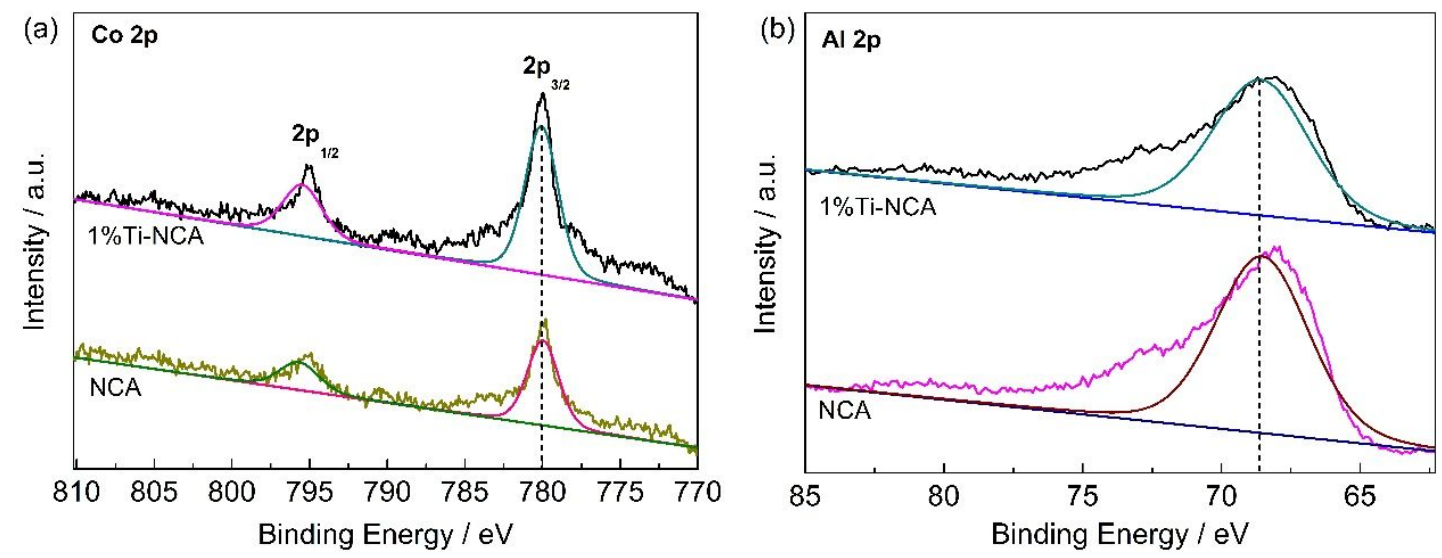

Figure. S2 XPS spectra and fitted results of (a) Co $2 p$ and (b) A1 $2 p$ of the NCA and $1 \%$ Ti-NCA samples. 


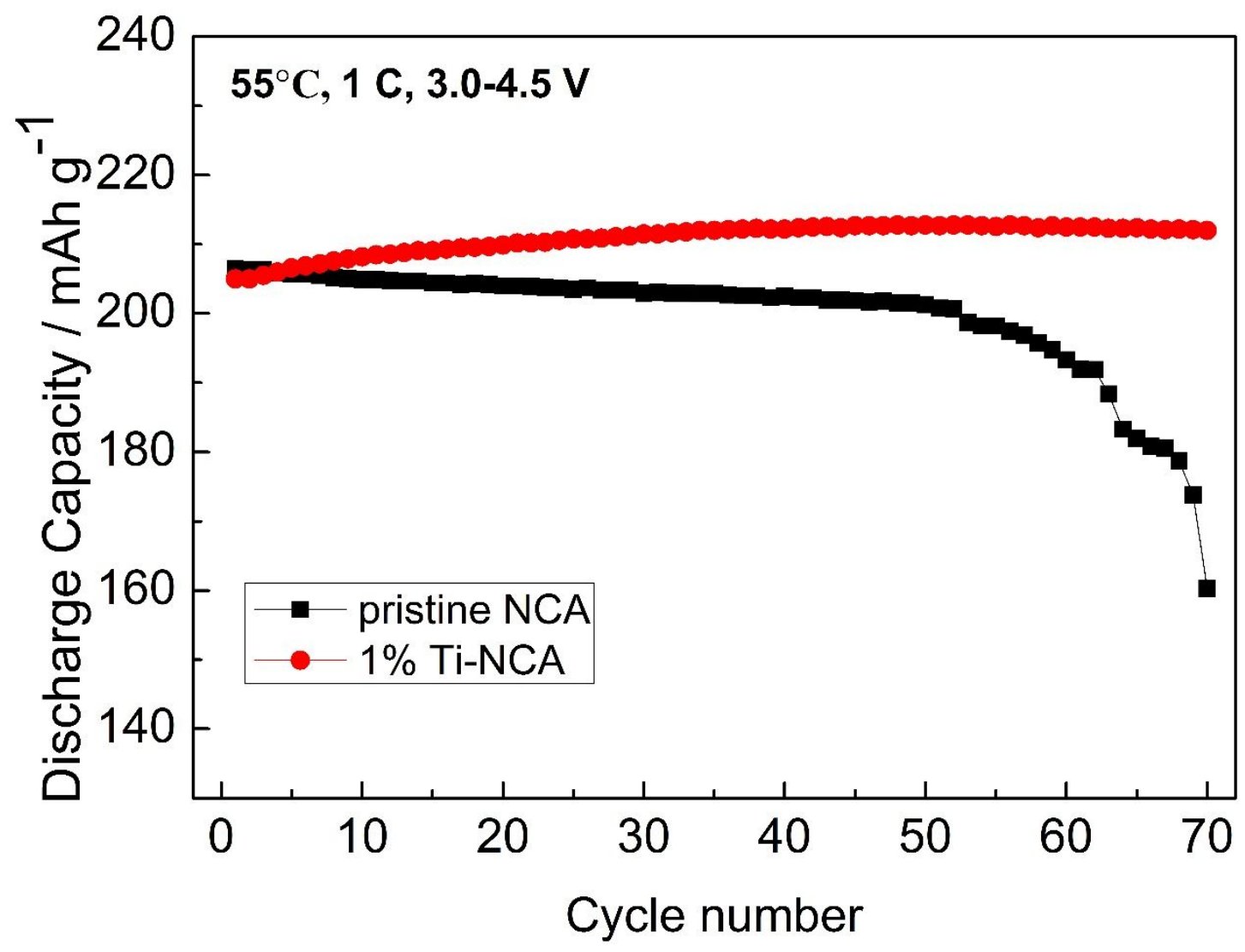

Figure. S3 Cyclic performance between 3.0 and $4.5 \mathrm{~V}$ at $55^{\circ} \mathrm{C}$ under $1 \mathrm{C}$ for pristine NCA and $1 \%$ Ti-NCA. 


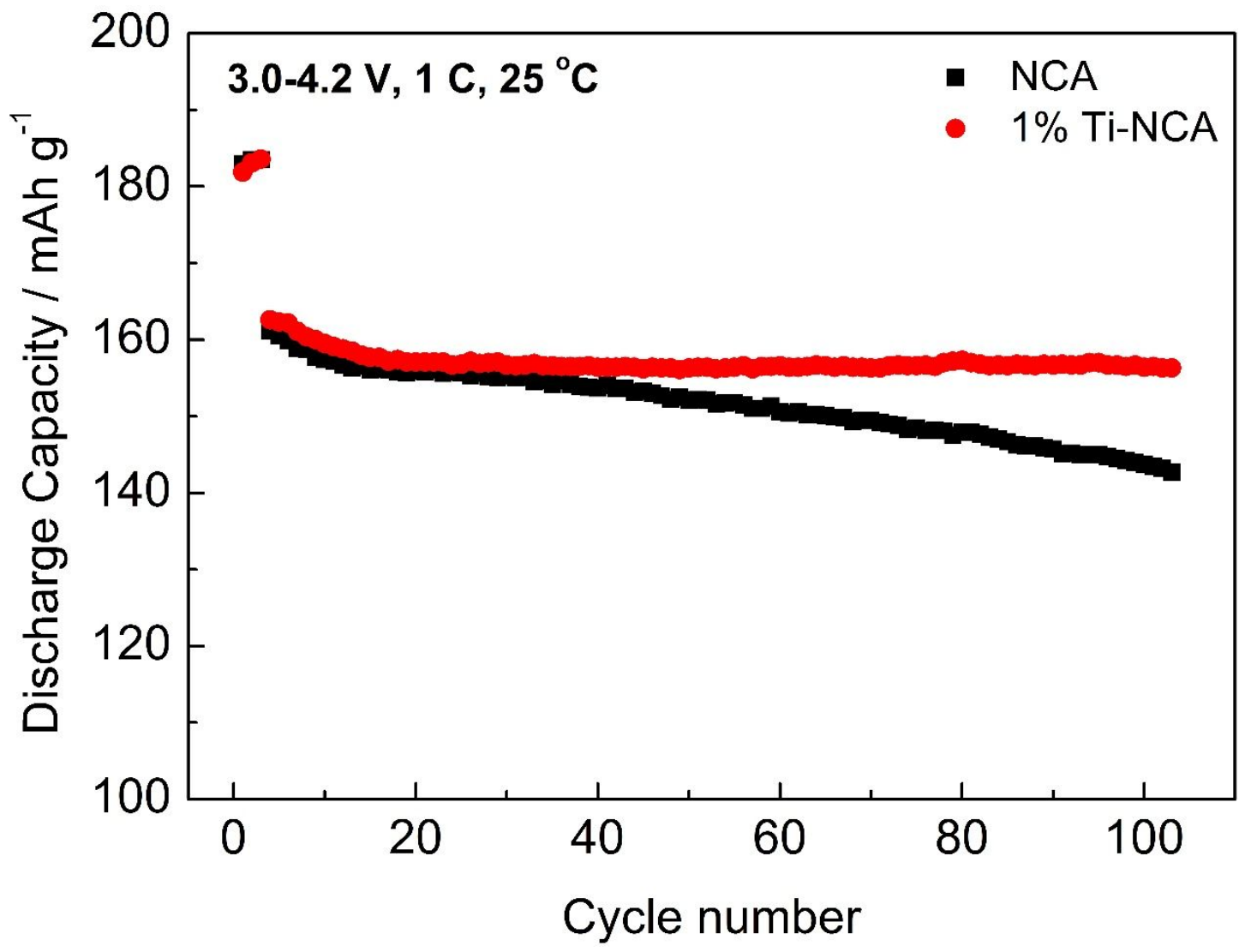

Figure. S4 Cyclic performance between 3.0 and $4.2 \mathrm{~V}$ at $25^{\circ} \mathrm{C}$ under $1 \mathrm{C}$ for pristine NCA and 1\%Ti-NCA. 


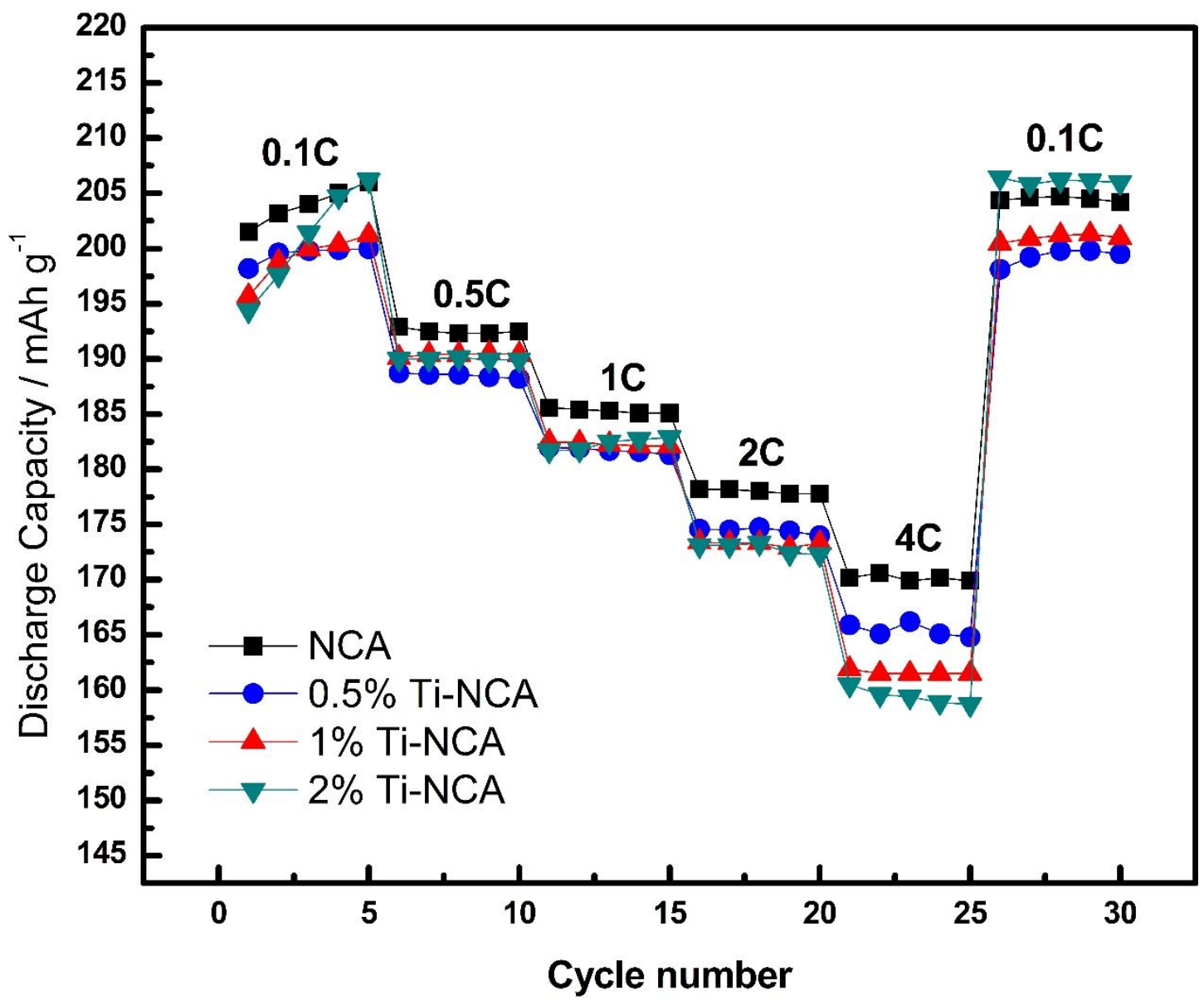

Figure. S5 Rate performance between 3.0 and $4.5 \mathrm{~V}$ at $25^{\circ} \mathrm{C}$ for all samples. 